WSRC-MS-95-0395

CONF- $9511128--19$

\title{
Evaluation of a Stack: A Concrete Chimney with Brick Liner
}

by

J. R. Joshi

Westinghouse Savannah River Company

Savannah River Site

Aiken, South Carolina 29808

J. A. Amin

R. A. Porthouse

Chimney Consultants

NH USA

A document prepared for FIFTH DEPARTMENT OF ENERGY NATUAL PHENOMENA HAZARDS MITIGATHN SYMPOSIUM at Denver from 11/13/95 - 11/17/95.

DOE Contract No. DE-AC09-89SR18035

This paper was prepared in connection with work done under the above contract number with the U.S.

Department of Energy. By acceptance of this paper, the publisher and/or recipient acknowledges the U.S. Government's right to retain a nonexclusive, royalty-free license in and to any copyright covering this paper, along with the right to reproduce and to authorize others to reproduce all or part of the copyrighted paper. 


\section{: DISCLATMER}

This report was prepared as an account of work sponsored by an agency of the United States Government. Neither the United States Government nor any agency thereof, nor any of their employees, makes any warranty, express or implied, or assumes any legal liability or responsibility for the accuracy, completeness, or usefulness of any information, apparatus, product, or process disclosed, or represents that its:use would not infringe privately owned rights. Reference berein to any specific commercial product, process, or service by trade name, trademark, manufacturer, or otherwise does not necessarily constitute or imply its endorsement, recommendation, or favoring by the United States Government or any agency thereof. The views and opinions of authors expressed herein do not necessarily. state or reflect those of the UnitedStates - Government or any agency thereof.

This report has been reproduced directly from the best available copy.

Available to DOE and DOE contractors from the Office of Scientific and Technical Information, P. O. Box 62. Oak Ridge, TN 37831; prices available from (615) $576-8401$.

Available to the public from the National Technical Information Service, U. S. Deparment of Commerce, 5285 Port Royal Rd., Springfield, VA 22161. 


\title{
EVALUATION OF A STACK: A CONCRETE CHIMNEY WITH BRICK LINER
}

\author{
Dr. Jagadish R. Joshi and Jayprakash A. Amin \\ Westinghouse Savannah River Company \\ 730-B, Aiken, SC 29808 \\ (803) $952-7077 \&-7070$ \\ Robert A. Porthouse \\ Chimney Consultants, 93 South Main Street \\ West Lebanon, NH 03794
}

(603) 298-6056

\begin{abstract}
A 200' tall stack, consisting of a concrete chimney with an independent acid proof brick liner built in the 1950's, serving the Separations facility at the Savannah River Site (SRS), was evaluated for the performance category 3 (PC3) level of Natural Phenomena Hazards (NPH) effects.

The inelastic energy absorption capacity of the concrete chimney was considered in the evaluation of the earthquake resistance, in particular, to compute the $F_{\mu}$ factor. The calculated value of $\mathrm{F}_{\mu}$ exceeded 3.0, while the seismic demand for the PC3 level, using an $F_{\mu}$ value of 1.5 , was found to be less than the capacity of the concrete chimney.

The capacity formulation. of ACI 307 was modified to incorporate the effect of an after design opening on the tension side.

There are considerable uncertainties in determining the earthquake resistance of the independent brick liner. The critical liner section, located at the bottom of the breeching opening, does not meet the current design recommendations. A discussion is provided for the possible acceptable values for the "Moment Reduction Factor", $R_{W}$ or $F_{\mu}$ for the liner.

Comments are provided on the comparison of stack demands using response spectra (RS) versus time history (TH) analysis, with and without soil structure interaction (SSI) effects.
\end{abstract}

\section{INTRODUCTION}

The Canyon building, constructed in the 1950 's, is a radiochemical plant for purex processing of irradiated natural and depleted uranium targets for the separation and recovery of ${ }^{239} \mathrm{Pu},{ }^{237} \mathrm{~Np}$ and ${ }^{238} \mathrm{U}$ at the SRS. As the terminal structure for the ventilation system, the exhaust stack has been classified as a safety class item in order to mitigate the consequences of criticality in the area safety analysis report (SAR).

The stack, built in the 1950's, was not designed for PC3 loads. The objective of this analysis was to determine the maximum NPH load values the stack can withstand. The loads were determined as the peak ground acceleration (PGA) for seismic events and the fastest miles per hour (mph) wind speed for straight wind and tornado events.

\section{'DESCRIPTION}

The $199^{\prime} 4^{\prime \prime}$ tall concrete chimney has a top outside diameter of $12^{\prime} 7^{\prime \prime}$ which tapers uniformly to $17^{\prime} 101 / 8^{\prime \prime}$ at the base. The concrete wall thickness varies from 6 " at top to $11^{\prime \prime}$ at the base. The 199' 4 " tall independent acid proof brick liner has a constant inside diameter of $10^{\prime}$. The liner wall thickness is $4 "$ throughout the top $50^{\prime}, 8^{\prime \prime}$ in the intermediate $125^{\prime}$ and $12^{\prime \prime}$ in the remaining height.

Openings occur in the chimney and liner near the base of the stack to permit penetration of the breeching duct leading from the air tunnel. The chimney opening is $7^{\prime} 6^{\prime \prime}$ wide $X 16^{\prime}$ high 
with the bottom at $1^{\prime} 31 / 2^{\prime \prime}$ above the base. In addition smaller openings, $2^{\prime}$ square, in the chimney and liner were cut at $180^{\circ}$ to the existing breeching opening, to accommodate installation of an annulus pressurization system in the 1980s.

According to the design drawings, there is a clear distance of about 5 inches between the outside of the liner and the inside of the concrete chimney at the top.

The structure is supported on a $3^{\prime} 2^{\prime \prime}$ high solid concrete pedestal which houses a stainless steel pan and drain pipes to carry off condensation. The thickness of the pedestal envelopes the outside of the concrete chimney to the inside of the brick liner at base. Vertical reinforcing bars connect the concrete chimney to the pedestal and the pedestal to an octagonal concrete foundation mat. The mat is $5^{\prime} 6^{\prime \prime}$ thick with a plan dimension of $33^{\prime} 6^{\prime \prime}$ across the flats. Steel plate and frame structure houses and supports the breeching duct leading to the stack. The duct is partially supported off the mat; however it is not attached to the chimney.

The concrete chimney and brick liner are shown schematically in Figure 1. The pedestal and foundation mat are shown in Figure 2.

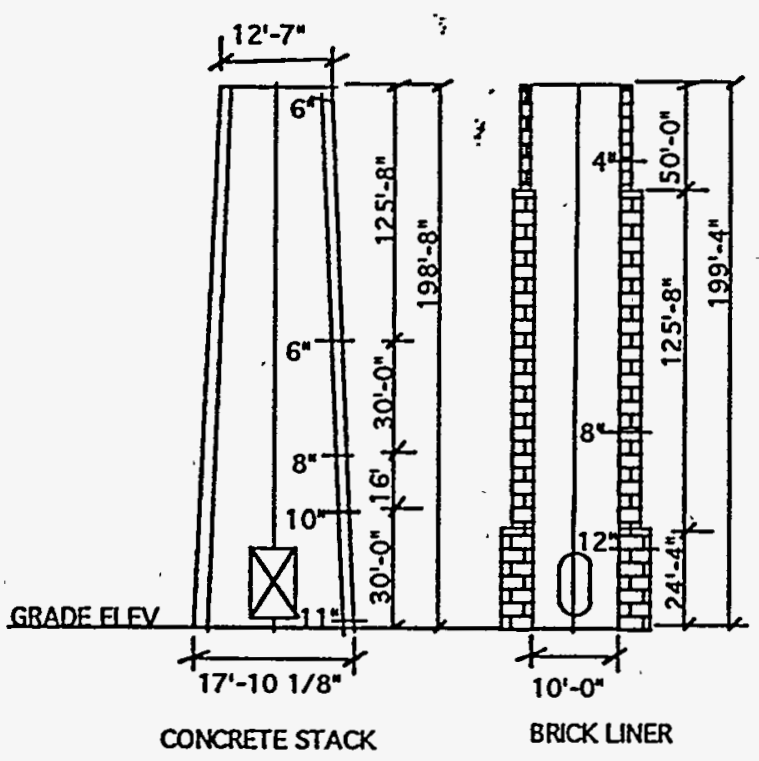

Figure 1: Vertical Cross Section Through Chimney and Liner

\section{ANALYSIS}

\section{LOADING REQUIREMENTS}

The design PC3 straight wind and tornado speeds are 109 and $137 \mathrm{mph}$, respectively.

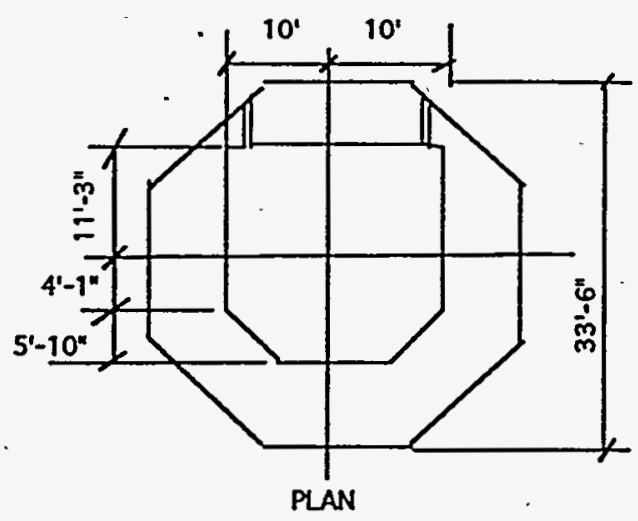

GRADE EEV

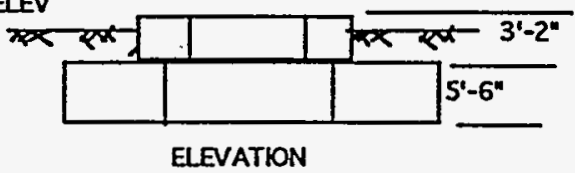

Figure 2: Pedestal and Foundation Mat

Blume [1] response spectra (RS) anchored at $0.20 \mathrm{~g}$, shown in Figure 3 , is considered as the . seismic input requirement for PC3. RS analysis is performed using Blume spectra for 7 percent damping anchored at the desired PGA. The free field seismic time history (TH) which envelopes the Blume RS anchored at the desired PGA, in the 4 to 7 percent damping range, is used in the TH analysis.

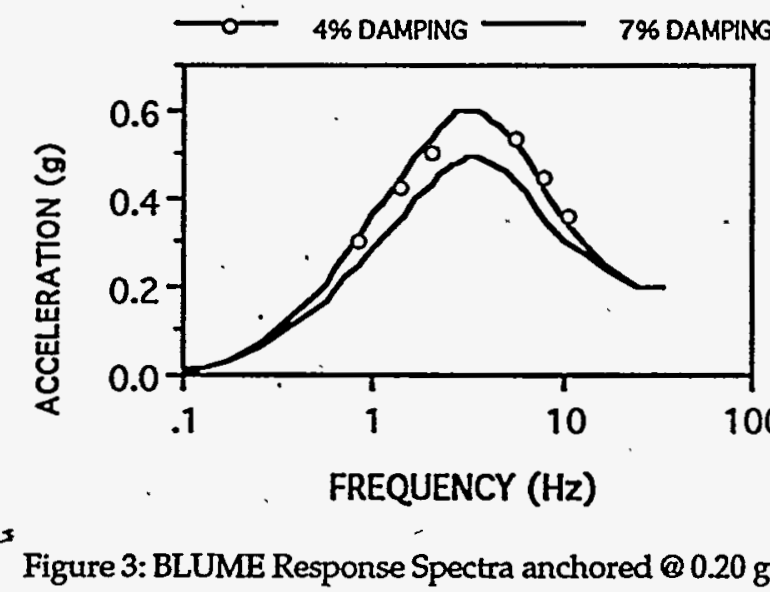

In the loading combinations for the stack structural elements, a load factor of 1.0 is used which is consistent with the criteria for PC3 load combinations. The load factor on dead load is taken as 0.9 .

\section{NATIONAL STANDARDS}

The national consensus standards, chimney standard, $\mathrm{ACI} 307$ [2] and the draft ASTM standard liner guide [3] are used for 
obtaining demands and capacities, except as modified, where necessary.

The capacity of concrete chimney sections with or without designed openings is obtained per $\mathrm{ACI} 307$ procedures except as indicated below; accordingly, a strength reduction factor of 0.80 is used for the flexural capacity of the chimney cross section.

For the moment capacity of a chimney section with two openings (one, a designed opening on the compression side and a smaller after-design opening on the tension side), equations are derived. Equations of $\mathrm{ACI} 307$ are revised to incorporate the fact that for an after-design opening on the tension side, the amount of steel that would have been there, if there were no opening, is not replaced by extra steel on either side of the opening, as is the case in a designed opening. The modified equations are given in Appendix A.

The concrete chimney section contains only one layer of horizontal steel, the location of which is not known. For the purposes of calculating the circumferential bending moment capacity it is assumed that the vertical steel is in the middle of the sectional thickness and that the horizontal steel is outside of the vertical steel. The latter is consistent with known chimney construction practice. For this configuration, the moment capacity causing tension on the inside face is less than that causing tension on the outside. The maximum demand circumferential moment due to wind on the chimney section causing tension on the inside face is more than that causing tension on the outside in accordance with ACI 307 [2]. Thus, only the moment capacities causing tension on the inside face are explicitly calculated for circumferential bending using a strength reduction factor of 0.90 .

For the capacity of the brick liner section with an opening on the compression side, equations are derived to obtain the moment capacity of the section, given a maximum allowable stress in the brick masonry in accordance with the draft ASTM brick liner guide [3]. Only contributions from the compression side are considered. The derivation is similar to the concrete chimney formulation based on working stress methodology with a reinforcing steel ratio of zero.

In determining the flexural capacity of the brick liner sections the dead load is reduced by a factor of 0.9. Flexural strength reduction factor is taken as unity. The liner guide [3] is silent on thèse subjects.

The draft liner guide [3] recommends values of the modulus of elasticity and masonry strength as 2,500 kips per square inch (ksi) and $5,300 \mathrm{psi}$, respectively. The latter leads to the maximum allowable stress of 795 psi for dead load combined with the seismic load. This value is used in the computation of the capacity of the liner sections except where adequate factors of safety are not met on the critical buckling stress or against overturning.

\section{SEISMIC DEMAND}

In recognition of the inelastic energy absorption capacity of ductile structures DOESTD-1020 [4] recommends the use of an $\mathrm{F}_{\mu}$ factor for PC3 and PC4 structures; the inelastic seismic demand loads are obtained by dividing the elastic seismic response by $F_{\mu}$. For obtaining the seismic demand loads on the concrete chimney the $F_{\mu}$ factor is calculated.

In the draft ASTM brick liner guide [3] the response spectra method using modal superposition is recognized as the preferred method of analysis (relative to an equivalent static approach) for obtaining the seismic loads on the liner sections. The draft guide stipulates that brick liners are not used for zones 3 and 4, using the ASCE 7 [5] (or UBC) language. Section 7.4.4 of the guide provides for the acceptability of an "earthquake reduction factor" of 0.75 ; that is, the demand shears or moments on the liner are reduced by the factor, provided the risk of potentially extensive damage to the liner is understood. The draft guide further observes that this risk has been traditionally taken in the design of brick liners, as is demonstrated by the permissible use of a "Use factor" of 1.3 (as opposed to a normal value of 2.0 ) in earlier versions of $A C I 307$ (or UBC). The use of the earthquake reduction factor of 0.75 for the brick liner is equivalent to $a R_{W}$ or $F_{\mu}$ factor of $1.33(=1 / 0.75)$.

For estimating deflections of the concrete chimney or the brick liner for the seismic load case $F_{\mu}$ or $R_{W}$ are considered as 1.0; that is, the inelastic energy absorption is considered not to affect the maximum expected displacements.

\section{SSI Effects}

The soil profile, Table 1, and variations of the shear modulus and damping with soil strains, Figure 4, for the area, are 
used in this evaluation. The best estimate (BE) recommendations are based on a review of the soil profiles in the area.

\begin{tabular}{|c|c|c|c|c|c|c|c|}
\hline & & & & \multicolumn{4}{|c|}{$\mathrm{G}_{\max } \mathrm{ksf}$} \\
\hline $\begin{array}{c}\text { Elovation } \\
\text { it }\end{array}$ & $\begin{array}{l}\text { Layer } \\
\text { Thk } \\
\text { it }\end{array}$ & $\begin{array}{l}\text { PAosorte } \\
\text { Ratlo }\end{array}$ & $\begin{array}{c}\text { Density } \\
\text { PCF }\end{array}$ & $\begin{array}{l}V_{S} \\
\text { FPS }\end{array}$ & B.E. & L.B. & U.B. \\
\hline $311-268$ & 23 & 0.45 & 125 & 1000 & 3882 & 2824 & 5823 \\
\hline $286-218$ & 70 & 0.45 & 122 & 1200 & 5456 & 3492 & 8184 \\
\hline $216-185$ & 33 & 0.45 & 125 & 1350 & 7075 & 3113 & 10612 \\
\hline $185-180$ & 5 & 0.45 & 118 & 1350 & 6735 & 4311 & 10103 \\
\hline $180-111$ & 38 & 0.45 & 125 & 1400 & 7608 & 4870 & 11413 \\
\hline $141-124$ & 17 & 0.45 & 117 & 1400 & 7122 & 4558 & 10683 \\
\hline 124.74 & 50 & 0.45 & 125 & 1450 & 8162 & 5224 & 12243 \\
\hline
\end{tabular}

Table 1 Soil Profile

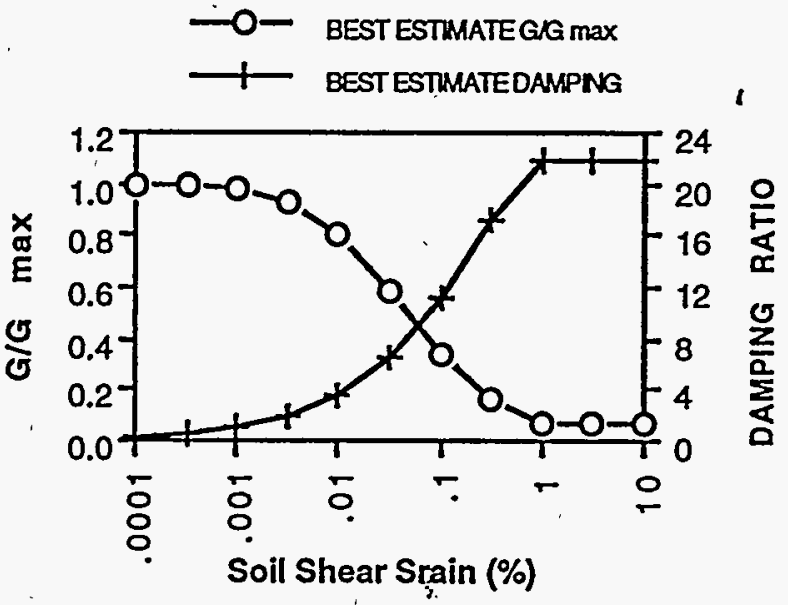
Figure 4: Variation of Damping and Shear Modulus
with Soil Strain

The effect of the input ground motion at various PGA ( $0.05 \mathrm{~g}$ to $0.20 \mathrm{~g})$ levels is found by using the SHAKE [6] program and the recommended dynamic soil properties. The resulting shear moduli in the top 30 feet are averaged to obtain the equivalent shear modulus of soil interfacing the foundation. The average shear modulus, Poison's ratio of the soil and the geometry of the foundation are used to obtain the equivalent spring and damping constants in three directions (the other lateral and the corresponding moment being not relevant and the torsional being inconsequential) using the state-of-the-art formulations [7]. The effect of 8 feet of foundation depth is incorporated in these calculations.

The calculations are repeated for upper bound (UB) conditions by multiplying the best estimates shear modulus properties for the individual layers by 1.5 ; for the lower bound (LB) the best estimate values are multiplied by
0.64 (instead of $0.67=1 / 1.5$ ) in order to envelop all available data for the soil properties in the region.

\section{COMPUTER CODES}

Structural analysis of the stack is performed using STRUDL [8] code. Some time history load cases were also analyzed using the GEMINI [9]; the results from the two codes matched closely. SHAKE [6] is used to obtain the appropriate dynamic soil properties.

\section{RESULTS}

\section{STRAIGHT WIND}

\section{Along Wind}

Flexural demand to capacity (D/C) ratios at. different elevations for the along wind loads resulting from wind speed of 105 $\mathrm{mph}$ are shown in Figure 5; the maximum $\mathrm{D} / \mathrm{C}$ is 0.96. The $A C I 307$ gust factor $G_{W}^{\prime}$ was 1.33 for the $105 \mathrm{mph}$ case.

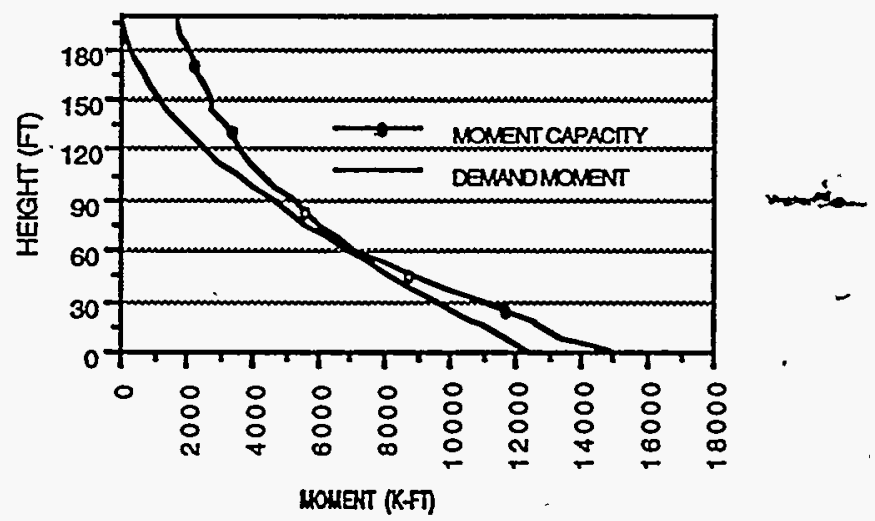

Figure :5 Along Wind Demand and Capacity

The critical section for $109 \mathrm{mph}$ occurs at elevation 61 feet where the $D / C$ ratio is 1.04 . $s$ The contribution of the mean wind load moment at the section is about 43 percent of the total moment. For the wind speed of $109 \mathrm{mph}$ the deflection at top is 3.68 inches which is less than the $5^{\prime \prime}$ clear distance between the concrete and the brick.

The critical section for the along wind condition. is not at the opening at the bottom of the chimney but at elevation 61 feet. This is because concrete compression does not control the design, the amount of vertical tensile steel does. The width of the after design opening near the base is small enough that the 
reduction in the moment capacity of the section is not significant.

As outlined in the $\mathrm{ACI} 307$, a portion of the along wind load is fluctuating; this is the portion on which the gust factor is applied. The fluctuating part is about $57(=100-43)$ percent of the total wind load for the critical section. If the concept of inelastic energy absorption capacity, generally used and accepted in the seismic demand calculation, were to be applied for the fluctuating part of the wind, with $\mathrm{F}_{\mu}$ equaling the conservative value of 1.5 for seismic condition, the wind load demand will go down to about $81(=43+57 / 1.5)$ percent. In other words the $D / C$ of 1.0 will be reached when the wind speed is about $117(=105 \times \sqrt{ }$ (1/0.81) ) mph.

The SSI has very little effect on the wind tornado loads on the chimney. The frequencies for the first three modes for the fixed base concrete chimney are $0.98,4.7$ and 11.4 hertz. These are changed to $0.9,4.25$ and 10.0 when the pedestal, foundation mat, and the soil spring and damping effects are considered.

The maximum $\mathrm{D} / \mathrm{C}$ for shear is less than 0.25 based on the nominal shear strength of the concrete section.

\section{Circumferential Wind}

For $109 \mathrm{mph}$ wind speed, the maximum D/C ratio for circumferential flexure, causing tension on inside, is 0.89 . This occurs in the top one and a half diameter height of the chimney where a high drag coefficient is given in $\mathrm{ACI}$ 307 to allow for the dominating local effects.

An evaluation of another stack at SRS indicated that the location of the horizontal steel can significantly affect the $D / C$ ratio on circumferential flexure with the $D / C$ exceeding unity very quickly. However it was determined that even where the $D / C$ ratio exceeded 3 , the anticipated result would be vertical cracks along partial heights of the chimney, and the formation of nominal sized concrete debris which may be separated from the chimney. That is, circumferential bending overstresses would cause local failures and not an overall cantilever type failure.

\section{Across Wind}

The first mode critical wind velocity is about $47 \mathrm{mph}$. Total bending moments, resulting from the across wind and the corresponding mean along wind moments, are computed using
$\mathrm{ACI} 307$ [2] procedures. The maximum $\mathrm{D} / \mathrm{C}$ is 0.36 . The second mode critical velocity exceeds $250 \mathrm{mph}$ and is therefore considered incredible.

\section{TORNADO}

Since the tornado wind load effects on the concrete chimney are evaluated in the same manner as the straight wind, the along wind results are also applicable for tornado wind. The chimney can withstand a tornado wind speed of $105 \mathrm{mph}$. For $137 \mathrm{mph}$ the maximum $\mathrm{D} / \mathrm{C}$ is 1.65 at elevation 61 feet. For the nominal assumed position of the circumferential steel the maximum $D / C$ ratio is 1.41.

There are some difficulties in applying the $\mathrm{ACI}$ 307-88 straight wind procedure to the tornado wind condition. The peak tornado wind speed, corresponding to the design tornado wind speed of $137 \mathrm{mph}$, is about 11 percent higher than the fastest mph. Section E.2 of DOE-STD-1020 [4] provides a relationship between the two. It may be argued that the ACI 307 procedure, though based on the fastest $\mathrm{mph}$ wind speed for straight wind, should be used with the peak tornado wind speed wher extended for the tornado case. In which case the error in using the fastest $\mathrm{mph}$ is on the non-conservative side. On the other hand, the gust factor calculation of the ACI 307 procedure for the tornado wind scenario is a significant overestimate, both in terms of the existence of the gust phenomenon and in the value of 1.5 percent used for damping. On the balance the use of the ACI 307 [2] procedure for tornado wind calculation is considered conservative.

The discussion related to the inelastic energy absorption and the fluctuating part of the straight wind load calculation is even more applicable for the tornado wind condition. If $F_{\mu}$ equals 3.5, the wind load demand will go down

to about $59(=43+57 / 3.5)$ percent. In other words the $D / C$ of 1.0 will be reached when the tornado speed is about $136(=105 \times \sqrt{ }(1 / 0.59))$ mph.

The potential scenario of local failures with vertical cracks and concrete debris, mentioned for the circumferential straight wind, is also more likely under the tornado conditions, because the wind speed is higher.

\section{Tornado Generated Missiles}

The thickness of the upper portion of the concrete chimney does not equal the 
minimum concrete thickness (8 inches) of the tornado missile barrier recommended for $\mathrm{PC} 3$ in Table 3-4 of DOE-STD-1020. Furthermore, the minimum circumferential reinforcing steel does not meet the recommended minimum. The most damaging missile causes only partial penetration and spalling.

\section{EARTHQUAKE}

Both RS and TH analyses were performed. The structural model incorporating SSI effects is shown in Figure 6.

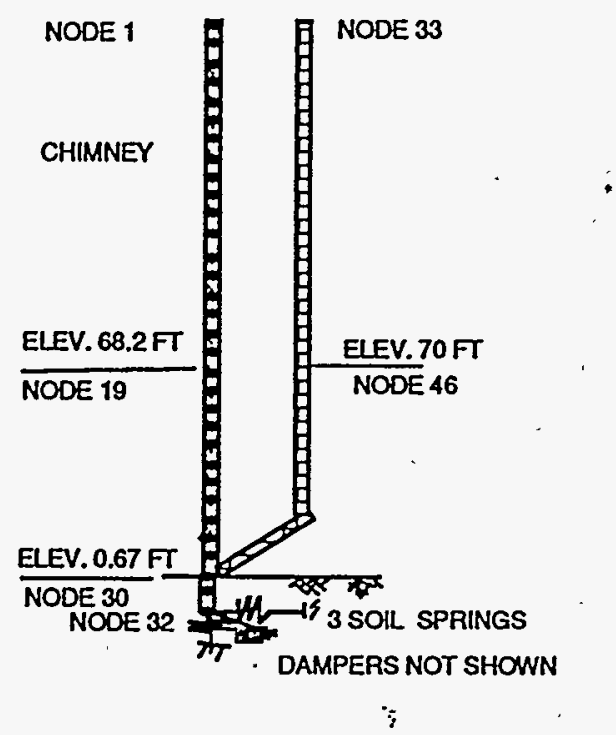

Figure 6: Combined Chimney and Liner Model

$$
\text { ? }
$$

The composite damping ratios for the first few modes of the model are about 10 percent.

$\mathrm{BE}$ response spectra for 7 percent damping for the top and at about $1 / 3$ height of the concrete chimney and the brick liner are shown in Figure 7. As expected, the local peaks of the response spectra correspond closely to the chimney and the liner frequencies.

\section{Earthquake on Chimney}

In order to calculate the $F_{\mu}$ factor for the concrete chimney the principles outlined in a Diablo Canyon report [10] are used. The application of the procedure for shear walls to a primarily flexural member is considered conservative. The critical chimney section is considered at 83 feet above the bottom of the chimney. In the equation for ductility the denominator is determined by the deflected shape at yield at the critical section, whereas the numerator by the deflected shape at the

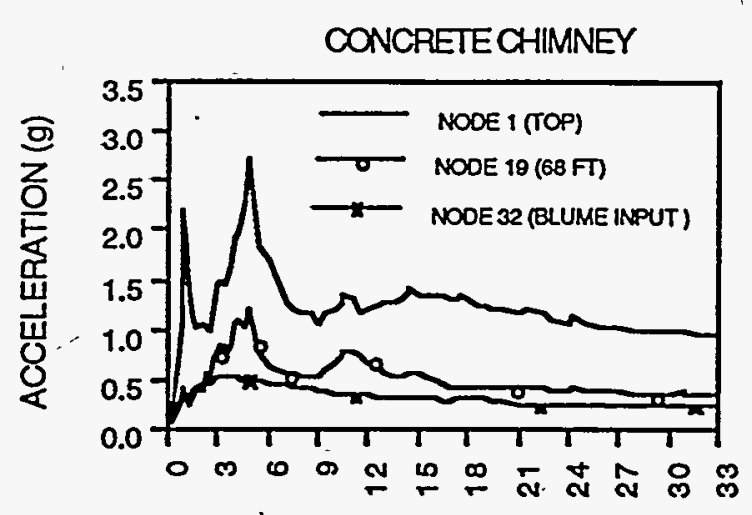

CONCRETECAMNEY

mode 2, Freq $0.90 \mathrm{~Hz}$

mode 4. Freq $4.25 \mathrm{~Hz}$

FREQUENCY $(\mathrm{H}-\mathrm{z})$

BRICK LINER

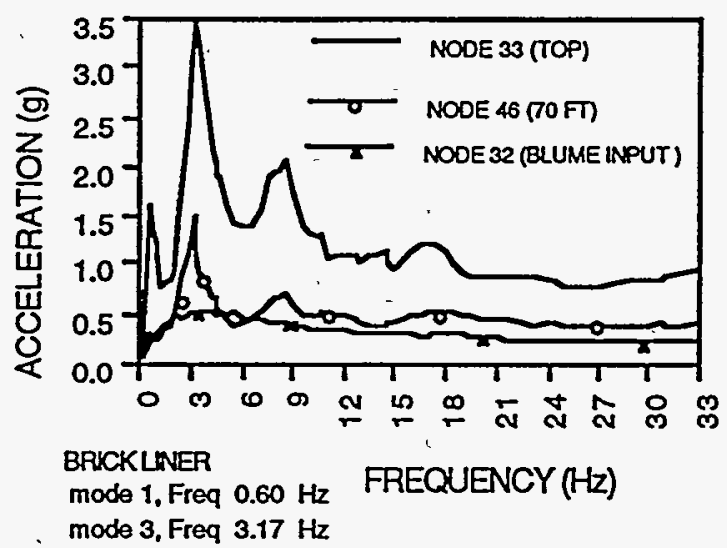

Figure 7: In-Structure Response Spectra

onset of significant strength reduction, both requiring the distribution of weight. The latter shape is determined by stipulating a plastic hinge at the critical section. The permissible rotation at the plastic hinge is obtained as 0.05 using Appendix $\mathrm{C}$ of $\mathrm{ACI} 349-85$ [11] as a guide. Based on the permissible rotation the available ductility is found to be above 15 . The factor $F_{\mu}$ is the average of the values obtained using the effective Riddel-Newmark method s and that using the spectral averaging method.

A ductility of 8 , a ratio of ultimate to yield moment capacity of the section of 1.125 , and the input spectra (Blume with 7 percent damping anchored at $0.20 \mathrm{~g}$ ) are used in the $F_{\mu}$ calculations. The calculated value of $F_{\mu}$ is 3.5 . A conservative value of 1.5 is used for $F_{\mu}$ in determining the seismic demand for the concrete chimney.

For the fixed base analysis of the concrete chimney with a 7 percent damping Blume spectra input anchored at $0.20 \mathrm{~g}$, the maximum 
D/C of .88 occurs at 61 feet above base. Deflection at the top for this case is $4.9=3.68$ $X 0.20 / 0.15$ ) inches.

For the combined model incorporating the brick liner, pedestal, foundation mat, and soil springs and dampers, for a PGA of $0.20 \mathrm{~g}$, the maximum $D / C$ for the chimney of $0.84,0.82$ and 0.77 occur at about the same height for UB, BE and LB soil properties, corresponding to the shear moduli of $5,312,3,400$ and 2,027 ksf, respectively.

\section{Earthquake on Liner}

For the fixed base analysis of the brick liner with a 7 percent damping Blume spectra input anchored at $0.06 \mathrm{~g}$ the maximum $\mathrm{D} / \mathrm{C}$ ratio of 0.83 , with a reduction factor of 0.75 , occurs at the bottom of the opening. Deflection at the top is $4(=3 / 0.75)$ inches.

For the combined model incorporating the concrete chimney, pedestal, foundation mat, and soil springs and dampers, for a PGA of $0.06 \mathrm{~g}$, the maximum $\mathrm{D} / \mathrm{C}$ of $0.9,0.93$ and 0.96 occur at the bottom of the base opening in the liner for $U B, B E$ and $L B$ soil properties, corresponding to the shear moduli of 5,654, 3,700 and $2,311 \mathrm{ksf}$, respectively.

For most of the brick liner height, other than through the opening, the moment capacity was controlled by the factor of safety requirement of 1.30 against overturning, rather than the maximum compressive stres's of $795 \mathrm{psi}$. The buckling criteria controlled the capacity in the top $\mathbf{4 0}$ feet of the liner primarily because of the distribution of load assumed in arriving at the, buckling stress in the draft liner guide [3].

\section{Chimney and Liner Coupled}

In this scenario the concrete chimney and the brick liner are coupled at the top for lateral displacement. This occurs if the chimney and the liner have deflected 5 inches relative to each other. The overall structural integrity of the chimney and the liner is assumed to remain in tact.

For the coupled model including the pedestal, foundation mat, and springs and dampers the maximum $D / C$ of 1.0 is reached at the bottom opening in the liner for the LB case with a PGA of $0.086 \mathrm{~g}$ and a reduction factor of 0.75 . The corresponding $D / C$ ratios for the remaining liner and chimney are significantly lower. The lateral load transfer at the top between the brick and the concrete is about 15 kips. The deflection of the system at the top is about 6.7 $(=5 / 0.75)$ inches.

In the event of liner collapse the extent of the damage to the concrete chimney will depend on the failure mechanism of the liner. One scenario of liner collapse was investigated. If the liner bricks were to spread as a fluid inside the annular space between the chimney and liner, the chimney wall is subjected to circumferential tension causing failure of the chimney.

\section{DISCUSSION OF RESULTS}

\section{EARTHQUAKE ON CHIMNEY}

The value of 8 used for the available ductility in the calculation of $F_{\mu}$ of 3.5 corresponds to a rotational limit of 0.026 , or a deflection of about 38 inches at the top of the 200 feet high chimney. The value of $F_{\mu}$ of 1.5 used in the seismic evaluation corresponds to a ductility value of less than 2 which in turn corresponds to a rotation at the plastic hinge of less than 0.005 or a total deflection less than 9 inches at the top.

The lap lengths provided for the vertical reinforcing bars in accordance with the design drawings are at least 33 percent more than those required for a class $B$ splice by the current standard ACI 318-89 [12]. Fifty percent of the total vertical steel is spliced at a typical chimney section. Since there is one layer each of horizontal and vertical steel in the concrete chimney wall, the vertical steel is likely to be in the middle of the wall thickness in which case the cover. is likely to be at least 2 inches. Thus the lap length and cover are adequate to develop a yield stress of at least $53 \mathrm{ksi}$ for a 40 ksi design yield strength.

A high calculated value of $F_{\mu}$ is to be expected ' in chimneys considering that the vertical steel ratio of 0.0025 has been used as a minimum in the chimney industry and generally has been increased significantly only near the openings. Furthermore, unlike in a beam, this ratio is for the total vertical steel distributed over the whole annular section, including the compression area. The minimum tensile steel ratio required in a beam member per [12] is 0.005 for a yield stress of $40 \mathrm{ksi}$. Concrete chimney sections are typically grossly under-reinforced. Thus for the ultimate load condition of the critical section at elevation 83 feet, the limiting strain of 0.07 is reached prior to the 
compression strain of 0.003 in the extreme concrete fiber.

\section{EARTHQUAKE ON LINER}

The critical section for the brick liner is at the bottom of the breeching opening. If it were a full circular liner (no openings) the D/C would have reduced from 0.96 to 0.76 for a 7 percent Blume spectral input anchored at $0.06 \mathrm{~g}$, with a reduction factor of 0.75 . That is, if the opening were strengthened or if the earthquake is not in the direction of the breeching, the brick liner can withstand an earthquake of about $0.076 \mathrm{~g}(=0.06 \times 0.96 / 0.76)$.

The width of the opening (6.65 feet) at the critical section of the brick liner exceeds the limit of 0.50 times the inside diameter of the liner (10 feet) recommended in the draft liner guide [3]. Furthermore the jamb reinforcing provided in the brick liner is not consistent with those recommended in the liner guide. Flexural resisting moments were obtained as a function of the maximum stress in compression for a typical brick liner section without openings and for the critical section at the breeching with opening. For the section without openings at elevation 53 feet, the ratio of the peak resisting moment to the moment where the maximum stress of 795 psi is reached is nearly 1.0; the ratio increases to 1.2 for the section with the opening at elevation 15 feet. The comparison is shown in Figure 8. There is more margin against collapse when'the opening was considered, if the stress was fimited to 795 psi, relative to when there was no opening.

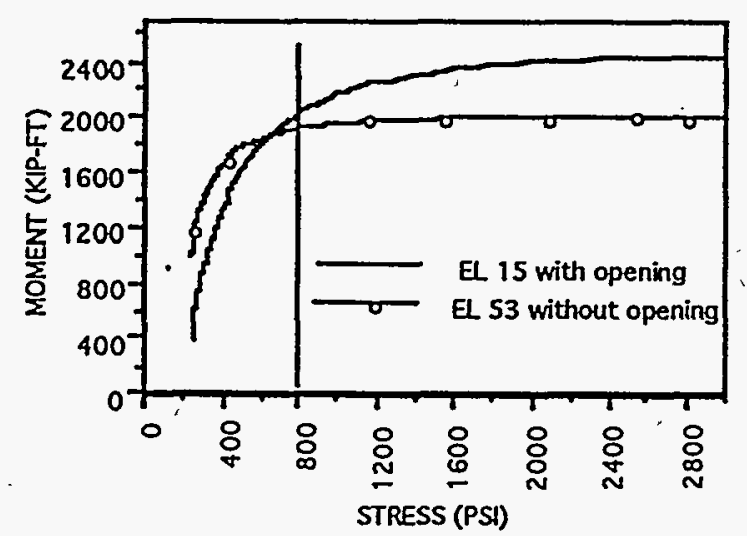

Figure 8: Moment Vs Maximum stress for Brick Liner

The SSI has some effect on seismic loads on the liner; the maximum D/C with SSI is 0.96 (for LB) compared to 0.83 for the fixed base.
For a seismic event with a PGA of $0.06 \mathrm{~g}$, the maximum calculated displacements for the concrete chimney and brick liner at the top are $1.44(=4.8 \times 0.06 / 0.20)$ and 3.0 inches, respectively, giving a relative displacement of 4.44 inches.

For unreinforced masonry shear walls with load bearing wall system, the $R$ factor given in Table 9.3-2 of ASCE 7 [5] is 1.25. As noted in the commentary in the reference, $R_{W}$ value of UBC (or SEAOC), corresponds generally to 1.5 times the $R$ value of ASCE 7. Thus a case could be made to use an earthquake reduction factor for the brick liner of about $0.53(=1 /(1.25 \times 1.5)$. In that case the brick liner could withstand a PGA of about $0.085 \mathrm{~g}(=0.06 \times 0.75 / 0.53)$.

In Table 1-I of SEAOC [13] $R_{W}$ of 5 is recommended for reinforced concrete chimneys. For all self-supporting structures not covered in the table the recommended $R_{W}$ is 4 , the minimum value for any structure being 3 . For the minimum value of $R_{W}$ for the brick liner, the earthquake reduction factor would be 0.33 (= $1 / 3)$, and the corresponding PGA the brick liner could withstand is $0.136 \mathrm{~g}(=0.06 \mathrm{~g} \times 0.75 / 0.33)$.

Paulay and Priestley discuss in Section 2.3.4 of [14] the relationship between the ductility of an inelastic system, $\mu$, and the force reduction factor, R, for seismic considerations. For structures with natural periods greater than that corresponding to the peak elastic spectral response for the seismic input, equal displacement concept is applicable, leading to, $\mu$ approximately equals $R$. For the brick liner, the first mode period is about 1.6 second $(=1$ / $0.63)$ whereas the peak input response spectral period is about 0.33 second.

The modulus of elasticity of the brick liner masonry of $2500 \mathrm{ksi}$ used in this analysis is higher than the values used in [14] for unreinforced masonry, expressed as a factor times the compressive strength. This may have added some conservatism in the demand load calculations.

There are significant uncertainties about the behavior of the brick liner under seismic events. At or below $0.045 \mathrm{~g}$ PGA level the liner is likely to see little or no damage. At $0.06 \mathrm{~g}$ PGA level the liner is expected to experience some damage including cracking. The critical section is the bottom of the breeching opening with moment causing compression at the opening. The PGA level will be higher if a higher damping level 
were used in the input Blume spectra (relative to the 7 percent considered). If the direction of the earthquake event is not primarily parallel to the breeching, then this PGA rises to $0.09 \mathrm{~g}$. For PGA between about $0.06 \mathrm{~g}$ and $0.14 \mathrm{~g}$, the liner is expected to undergo significant damage which results into inelastic energy absorption and thereby reduces the increase in forces. The exact mode of failure of the brick liner or PGA at failure cannot be determined.

\section{CHIMNEY AND LINER COUPLED}

The likelihood of the chimney and liner being coupled at the top is high for a seismic event beyond a PGA of $0.06 \mathrm{~g}$. However the functioning as a coupled system will depend considerably on whether the event will cause a local failure of the breeching opening before the liner can lean over to the chimney. With the coupled system, the brick liner opening will reach its capacity at a PGA of about $0.086 \mathrm{~g}$, and the liner as a cylinder at a PGA of about $0.12 \mathrm{~g}$, with a reduction factor of 0.75 .

\section{COMPARISON OF RS AND TH RESULTS}

The seismic results were primarily based on the RS analysis: TH analysis was also performed for some cases. The Blume spectra with 4 to 7 percent damping, Figure 3 , was used as the target spectra for developing the $\mathrm{TH}$.

In the critical area of the concrete chimney the TH demand with SSI is 14 percent lower than that from a fixed base RS analysis, as was expected. Demands from TH âre generally 2 to 8 percent higher than those from the RS analysis using the RS from the TH, both incorporating SSI; this was not expected. The latter demands are slightly higher than those from Blume RS with SSI, as expected.

Similar comparisons for the brick liner also give some unexpected results, which need further study. In the critical area of the liner TH demand with SSI is about 10 percent higher than that from a fixed base RS analysis. Demands using the RS from $\mathrm{TH}$ are 7 to 10 percent higher at the base than those from $\mathrm{TH}$, as expected. The TH values are about 10 percent higher than the Blume RS values, both considering SSI.

The time history analysis does not always reduce seismic demand loads on the stack.

\section{CONCLUSIONS}

\section{STRAIGHT WIND / TORNADO}

The maximum $\mathrm{D} / \mathrm{C}$ ratios for $\mathrm{PC} 3$ wind and tornado speeds of 109 and $137 \mathrm{mph}$ are 1.04 . and 1.65 , respectively. If the concept of inelastic energy absorption capacity is applied to the fluctuating part of the loads $\left(F_{\mu}=1.5\right)$ the maximum $D / C$ ratios reduce to 0.94 and 1.49.

For circumferential bending the maximum $D / C$ ratios near the top are 0.89 and 1.41 for the $\mathrm{PC} 3$ wind and tornado loads, respectively, for a nominal assumed position of the reinforcing steel.

\section{EARTHQUAKE}

For the concrete chimney the maximum $D / C$ ratio for $P C 3$ earthquake load is 0.84 based on a conservative value of $F_{\mu}$ of 1.5 . However earthquake on chimney alone is unrealistic.

For the brick liner the $D / C$ of 1.0 is reached at the bottom of the opening for a seismic event with a PGA of $0.06 \mathrm{~g}$ based on a moment reduction factor of 0.75 as recommended in a draft liner guide.

A lower moment reduction factor may be justified in which case the brick liner may be able to withstand a PGA as high as $0.14 \mathrm{~g}$. The brick liner is likely to undergo significant damage between a PGA of $0.06 \mathrm{~g}$ to $0.14 \mathrm{~g}$.

The extent of damage to the concrete chimney due to the collapse of the brick liner cannot be determined exactly. If the liner were to spread inside the chimney, the wall of the chimney could fail in circumferential tension.

\section{REFERENCES}

"I1] URS/Blume (1984), Update of Seismic Criteria for the Savannah River Plant, Engineering Design for Maximum Resistance Facilities, Vol. 2.

[2] ACI 307-88 and ACI 307-88R, Standard Practice for the Design and Construction of Cast-in-place Reinforced Concrete Chimneys and Commentary, 1988.

[3] Draft approved by the ASTM C15.09 Task Force on Brick Liner Design (1994), Standard Guide for The Design and 
Construction of Brick Liners for Industrial Chimneys.

[4] U. S. Department of Energy, Natural 'Phenomena Hazards Design and Evaluation Criteria for DOE Facilities, DOE-STD-1020-94, 1994.

[5] ASCE 7-93, Minimum Design Loads for Buildings and Other Structure, 1994.

[6] Schnabel, P. B., J. Lysmer, and H. B. Seed (1972), SHAKE: A Computer Program for Earthquake Response Analysis of Horizontally Layered Sites, EERC 72-12, University of California, Berkeley.

[7] Das, B. M. (1993), Principles of Soil Dynamics, Chapter 5, PWS-Kent Publishing.

[8] Georgia Institute of Technology (1994), GTSTRUDL, A Finite Element Analysis Computer Code.

[9] Murray, R. C. (1984), GEMINI - A Computer Program for Two and Three Dimensional Linear Static, and Seismic Structural Analysis", LLNL.

[10] Kennedy, R. P., D. A. Wesley, and W. H. Tong (1988), Probabilistic Evaluation of the Diablo Canyon Turbine Building Seismic Capacity using Nonlinear Time History Analyses, Pacific Gas \& Electric Company, Report Number 1643.01.

[11] ACI 349-85, Code Requirements for Nuclear Safety Related Concrete Structures, 1985.
[12] ACI 318-89, Building Code Requirements for Reinforced Concrete, 1989.

[13] Seismology Committee, Structural Engineers Association Of California (1990), Recommended Lateral Force Requirements and Commentary.

[14] Paulay, T., and M. J. N. Priestley (1992), Seismic Design of Reinforced Concrete and Masonry Buildings, J. Wiley.

\section{APPENDIX A}

$2 \times \beta_{2}=$ angle subtended by the tension side opening; the location of this opening is such that had there been steel it would have yielded.

For a chimney section with a tension side opening at $180^{\circ}$ with respect to the bigger compression side opening the nominal moment strength is given by $\mathrm{ACI} 307$ [2] equations with the following modifications:

Equation (5-5) in $\mathrm{ACl} 307$ [3] to read

$\lambda_{1}=\mu+\phi-\pi+\beta_{2}$, and

equation (5-14) in ACI 307 [3] to read

$K=\sin \phi+\sin \mu+\left(\pi-\beta_{2}-\phi-\mu\right) \cos \alpha$ 